\title{
Fcr1p Inhibits Development of Fluconazole Resistance in Candida albicans by Abolishing CDR1 Induction
}

\author{
Hui Shen, ${ }^{\#, a}$ Mao-Mao An, ${ }^{\#, b}$ De Jun WAng, ${ }^{a}$ Zheng Xu,${ }^{a}$ Jun-Dong Zhang, ${ }^{a}$ Ping-Hui GaO, ${ }^{a}$ \\ Ying-Ying $\mathrm{CAO},{ }^{a}$ Yong-Bing $\mathrm{CAO},{ }^{*}, a$ and Yuan-Ying JIANG ${ }^{*, a}$ \\ ${ }^{a}$ Department of Pharmacology, School of Pharmacy, Second Military Medical University; 325 Guo He Road, Shanghai \\ 200433, P.R. China: and ${ }^{b}$ Department of Clinical Pharmacology, Chinese People's Liberation Army General Hospital; 28 \\ Fu Xing Road, Beijing 100853, P.R. China. Received June 19, 2006; accepted September 16, 2006
}

\begin{abstract}
Overexpression of Candida drug resistance 1 (CDR1) gene in Candida albicans (C. albicans), an efflux pump, is one of the major mechanisms contributing to drug resistance. $C$. albicans for fluconazole resistance 1 protein (Fcr1p) is a member of the family of zinc cluster proteins homologous to Pdr1p and Pdr3p (pleiotropic drug resistance protein) mediating azole resistance in Saccharomyces cerevisiae (S. cerevisiae) by regulating the expression of pleiotropic drug resistance 5 (PDR5) homologous to $C$. albicans $C D R 1$. A previous study has showed that for fluconazole resistance 1 (FCR1) could also confer azole resistance in $S$. cerevisiae pdr1 pdr3 mutant by regulating PDR5. Therefore, we investigated the role of FCR1 in the development of $C$. albicans azole resistance in vitro and in vivo. Our results showed that Fcr1p inhibited fluconazole (FLC) resistance development in $C$. albicans through abolishing the induction of $C D R 1$ expression by FLC, and in contrast FLC resistance development was accelerated resulting from the deletion of $F C R 1$.
\end{abstract}

Key words Candida albicans; FCR1; CDR1; drug resistance

Candida albicans (C. albicans), the major opportunistic fungal pathogen in humans, causes diseases varying from superficial mucosal complaints to life-threatening systemic disorders. ${ }^{1-3)}$ Coincident with the increased use of antifungal drugs, the incidences of drug resistance have also increased. ${ }^{4-6)}$ In recent years, the development of multidrug resistance in clinical isolates has challenged effective treatment of the infections. Specifically, the extensive and repetitive use of antifungal azole derivatives such as fluconazole (FLC) has allowed C. albicans to utilize many mechanisms of resistance in order to ensure its survival. ${ }^{7,8)}$ This situation highlights the need for elucidating the mechanism of drug resistance in C. albicans to develop new antifungal agents.

Overexpression of efflux pumps, either ATP-binding cassette $(\mathrm{ABC})$ or major facilitator superfamily (MFS) transporters, has been shown to be one of the major mechanisms of drug resistance in clinical isolates because if causes active extrusion of the drug out of the cell. ${ }^{9-11)}$ The Candida drug resistance $1(C D R l)$ gene, which encodes an $\mathrm{ABC}$ efflux pump, is identified by complementation of the pleiotropic drug resistance 5 ( $p d r 5$ ) mutant, which is hypersensitive to cycloheximide, chloramphenicol, and azole drugs, in Saccharomyces cerevisiae $\left(S\right.$. cerevisiae) ${ }^{12)}$ C. albicans $c d r 1$ mutant resulted in increasing susceptibilities to azole drugs,${ }^{13)}$ which is consistent with the observation that overexpression of CDR1 contributes to the drug resistance of clinical isolates of $C$. albicans. ${ }^{6,14)}$ Furthermore, the existence of trans-regulatory factors of $C D R 1$ has also been suggested. ${ }^{15)}$ However, the molecular mechanism and the gene network regulating the expression of $C D R 1$ and drug resistance are poorly understood.

C. albicans Fcrlp (for fluconazole resistance 1 protein), a member of the family of zinc cluster proteins, is characterized by a highly conserved $\mathrm{Zn}(\mathrm{II})_{2} \mathrm{Cys}_{6}$ zinc finger motif within the N-terminal DNA binding domain (DBD). ${ }^{16)}$ Well known Pdr1p and Pdr3p (pleiotropic drug resistance protein) zinc cluster proteins regulate the expression of several multidrug $\mathrm{ABC}$ transporter genes including PDR5, $S N Q 2$, and YOR 1 , causing azole resistance in $S$. cerevisiae ${ }^{17-28)} \mathrm{C}$. albicans Fcrlp displays significant sequence homology with $S$. cerevisiae Pdrlp and Pdr3p, and it could confer azole resistance in $S$. cerevisiae $p d r 1 p d r 3$ mutant by regulating PDR 5. ${ }^{16)}$ We hypothesized that Fcrlp maybe involved in the development of $C$. albicans azole resistance as well as Pdr1p and Pdr3p in S. cerevisiae.

In the present study we investigated the role of Fcrlp in the development of $C$. albicans azole resistance and possible mechanisms in vitro and in vivo. The results showed that Fcr1p inhibited development of fluconazole resistance in $C$. albicans through abolishing the induction of $C D R 1$ expression by FLC, and in contrast FLC resistance development was accelerated resulting from the deletion of FCR1.

\section{MATERIALS AND METHODS}

Strains and Media C. albicans strain CAI4 (FCR1/ $F C R 1)$ and $C$. albicans strain FM7 (fcrl $1 \Delta:$ hisG/ fcrl $1 \Delta::$ his $G$, obtained by deleting both copies of the FCR1 gene in CAI4) were kindly provided by Dr. William A. Fonzi (Department of Microbiology and Immunology, Georgetown University, Washington, DC) and Dr. Martine Raymond (Institut de Recherches Cliniques de Montréal, Québec,

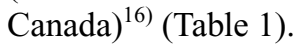

The strains were cultivated at $30^{\circ} \mathrm{C}$ under constant shaking $(200 \mathrm{rpm})$ in a liquid complete medium YPD consisting of $1 \%(\mathrm{w} / \mathrm{v})$ yeast extract, $2 \%(\mathrm{w} / \mathrm{v})$ peptone, and $2 \%(\mathrm{w} / \mathrm{v})$ dextrose. For agar plates, 2\% (w/v) Bacto agar (Difco, BD Biosciences) was added to the medium. Uridine $(20 \mu \mathrm{g} / \mathrm{ml})$ was added to ensure the growth of CAI4 and FM7.

Construction of $\boldsymbol{C}$. albicans FCR1 Expression Plasmids The YPB-ADH/FCR 1 plasmid was constructed by inserting a BglII-XhoI DNA fragment containing wild-type FCR1 into 
Table 1. Strains Used in the Study

\begin{tabular}{|c|c|c|}
\hline Strain & Genotype & Source \\
\hline CAI4 & ura $\Delta 3:: i m m^{434} /$ ura $3 \Delta:: i m m^{434}$ & $\begin{array}{l}\text { Gift from William } \\
\text { A. Fonzi }\end{array}$ \\
\hline CAI4[YPB-ADH] & $\begin{array}{l}\text { CAI } 4 \text { transformed by plasmid } \\
\text { YPB-ADHpt }\end{array}$ & This study \\
\hline FM7 & $\begin{array}{l}\text { ura } 3 \Delta:: \text { imm }^{434} / \text { ura } 3 \Delta:: \text { imm }^{434} \\
\text { fcr } 1 \Delta:: \text { hisG/fcr } 1 \Delta:: \text { hisG }\end{array}$ & $\begin{array}{l}\text { Gift from Martine } \\
\text { Raymond }\end{array}$ \\
\hline FM7[YPB-ADH] & $\begin{array}{l}\text { FM7 transformed by plasmid } \\
\text { YPB-ADHpt }\end{array}$ & This study \\
\hline FM7[YPB-ADH/FCR1] & $\begin{array}{l}\text { FM7 transformed by plasmid } \\
\text { YPB-ADH/FCR1 }\end{array}$ & This study \\
\hline
\end{tabular}

the YPB-ADHpt vector (a gift from Dr. Martine Raymond), which carries the $C$. albicans $A D H 1$ promoter and terminator regions, a $C$. albicans autonomously replicating sequence, and the CaURA3 marker. The plasmid YPB-ADHpt and the mutant plasmid YPB-ADH/FCR1 were used to transform FM7 cells by using the Yeast Transformation System 2 from Clontech (Palo Alto. CA, U.S.A.), while the plasmid YPBADHpt transformed CAI4 cell was used as control (Table 1). The positive colonies were then identified.

Quantitative Real-Time RT-PCR Total RNA was isolated from exponentially growing cultures with Trizol reagent (Invitrogen). First-strand cDNAs were synthesized from $2 \mu \mathrm{g}$ of total RNA in a $20-\mu \mathrm{l}$ reaction volume using a cDNA synthesis kit (TaKaRa) in accordance with the manufacturer's instructions. Real-time PCR was performed according to the procedure for real-time PCR kit (TaKaRa) using the Chromo4 System (Bio-rad).

Development of Resistance A single colony of the strains was respectively used to inoculate $10 \mathrm{ml}$ of YPD medium which was incubated overnight on a rotating drum at $30^{\circ} \mathrm{C}$. An aliquot of this culture containing $10^{6}$ cells was then transferred to $10 \mathrm{ml}$ medium containing $200 \mu \mathrm{g}$ of FLC (Pfizer Inc.), and the cells were incubated as described above. When the cultures reached a density of approximately $10^{8}$ cells $/ \mathrm{ml}$, aliquots containing $10^{6}$ cells were transferred into fresh YPD liquid medium containing the same respective FLC concentration and incubated as described above. At each passage, a 1-ml aliquot of the culture suspension was mixed with $0.5 \mathrm{ml}$ of $50 \%$ glycerol, and the mixture was frozen at $-70{ }^{\circ} \mathrm{C}$ for subsequent testing.

Antifungal Susceptibility Test The in vitro minimal inhibitory concentrations (MICs) of the compounds were determined by the micro-broth dilution method according to the methods defined by the National Committee for Clinical Laboratory Standards. ${ }^{29)}$ The drug MIC 80 was defined as the first well with an approximate $80 \%$ reduction in growth compared to the growth of the drug-free well.

The initial concentration of fungal suspension in RPMI 1640 (Sigma) medium was $10^{3}$ cells $/ \mathrm{ml}$, and the final concentrations ranged from 0.125 to $64 \mu \mathrm{g} / \mathrm{ml}$ for FLC. Plates were incubated at $30^{\circ} \mathrm{C}$ for $24 \mathrm{~h}$ without shaking. Optical density was measured at $600 \mathrm{~nm}$, and background optical densities were subtracted from that of each well.

Agar Diffusion Test The YPD agar plates were seeded with yeast cells $\left(3 \mathrm{ml}, 10^{6} \mathrm{cells} / \mathrm{ml}\right)$, plated at $30^{\circ} \mathrm{C}$ for $1 \mathrm{~h}$, then taken off the liquids, and again incubated at $30^{\circ} \mathrm{C}$ for
$1 \mathrm{~h}$. Drug solutions were spotted onto sterile Whatman paper disks on the agar. The indicated amount of the following drugs was applied to individual disks: FLC $2 \mu \mathrm{g}, 4 \mu \mathrm{g}, 8 \mu \mathrm{g}$, $16 \mu \mathrm{g}, 64 \mu \mathrm{g}$. The agar plates were incubated at $30^{\circ} \mathrm{C}$ for $48 \mathrm{~h}$. Assays were performed in duplicate.

Growth Curve Study The effect of FLC exposure in relation to time and concentration on the strains was determined in YPD liquid medium. FLC was added to the cultures, the final concentration of which was $20 \mu \mathrm{g} / \mathrm{ml}$. The growth was monitored by measuring the optical density $(600 \mathrm{~nm})$ of the cultures during the subsequent $48 \mathrm{~h}$.

Rhodamine 6G Efflux Active efflux of rhodamine 6G (R6G) was determined by a previously described protocol. ${ }^{30}$ Approximately $10^{7}$ cells from an overnight culture were incubated in $200 \mathrm{ml}$ of YPD medium and grown for $5 \mathrm{~h}$ at $30^{\circ} \mathrm{C}$. The cells were pelleted and washed three times with phosphate-buffered saline (PBS) buffer without glucose. The cells were resuspended in PBS buffer to the concentration of $10^{8}$ cells $/ \mathrm{ml}$, shaken at $30^{\circ} \mathrm{C}$ for $1 \mathrm{~h}$ to exhaust the energy, and then R6G was added to the final concentration of $10 \mu \mathrm{M}$ and incubated for $2 \mathrm{~h}$ at $30^{\circ} \mathrm{C}$. The cells were then washed three times with PBS before addition of glucose (final concentration, $2 \mathrm{~mm}$ ) to initiate R6G efflux. At specific intervals after the addition of glucose, the cells were centrifuged and $100 \mu \mathrm{l}$ supernatants were added into to 96 -well plates (BMG Labtechnologies). Rhodamine $6 \mathrm{G}$ fluorescence densities of the samples were measured at an excitation wavelength of $515 \mathrm{~nm}$ and an emission wavelength of $555 \mathrm{~nm}$.

Animal Studies BALB/c female mice weighing 18 to $20 \mathrm{~g}$ (Center of Experimental Animals, Second Military Medical University, Shanghai, China) were used in the study. All animals received humane care in compliance with the institutional animal care guidelines, and were approved by the Local Institutional Committee.

The susceptibility to FLC of strains CAI4[YPB-ADH], FM7[YPB-ADH], and FM7[YPB-ADH/FCR1] grown in FLC $(20 \mu \mathrm{g} / \mathrm{ml})$ for $25 \mathrm{~d}$ were tested in a murine model of disseminated candidiasis by inoculating $1 \times 10^{6}$ cells per mouse in the lateral tail vein. FLC therapy with the dose of $5 \mathrm{mg} / \mathrm{kg}$ by lateral tail vein injection was initiated at $24 \mathrm{~h}$ postchallenge. Control mice were given the same volume of sterile saline. After $5 \mathrm{~d}$ treatment, the mice were sacrificed and the kidneys were excised by a sterile technique, weighed, and homogenized in $2.0 \mathrm{ml}$ of sterile $0.9 \%$ saline. The homogenates were diluted by 10 -fold dilution in sterile saline, and $0.1 \mathrm{ml}$ of each dilution and the undiluted homogenate were cultured in triplicate on sabouraud dextrose agars (SDA). Culture plates were incubated for $48 \mathrm{~h}$ at $30^{\circ} \mathrm{C}$ and the number of colony-forming unit (CFU) per gram of tissue was calculated.

\section{RESULTS}

FCR1 Expression in FCR1 Overexpression, fcr1 Mutant and Their Parent Strain To confirm FCRl expression in FM7[YPB-ADH] which was $f c r 1$ mutant and FM7 [YPB-ADH/FCR1] which was FCR1 overexpression, realtime RT-PCR was applied in this study. There was no FCRI expression detected in FM7[YPB-ADH], while much higher expression was detected in FM7[YPB-ADH/FCR1] than their parent strain CAI4[YPB-ADH] (Fig. 1). 


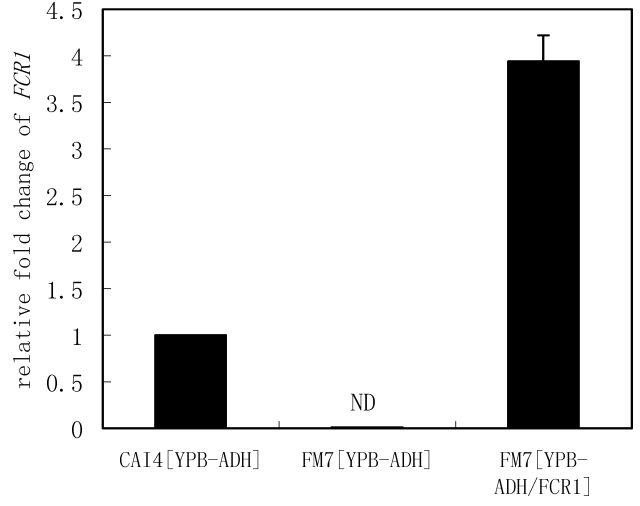

Fig. 1. Real-Time RT-PCR Analysis of FCR1 Expression in CAI4[YPBADH], FM7[YPB-ADH] and FM7[YPB-ADH/FCR1]

The level of mRNA isolated from CAI4[YPB-ADH] was defined as 1.0. The data are expressed as the mean \pm S.D.

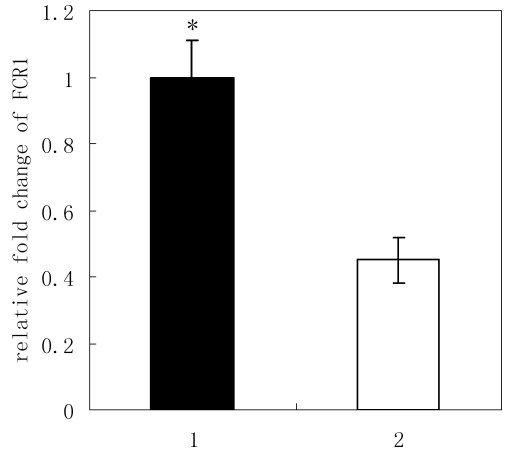

Fig. 2. Real-Time RT-PCR Analysis of FCR1 Expression in CAI4 after $25 \mathrm{~d}$ of FLC Exposure

Total RNA was isolated from CAI4 cultured in YPD absent (Bar 1) and present (Bar 2) $20 \mu \mathrm{g} / \mathrm{ml}$ FLC. The level of mRNA isolated from wild CAI4 was defined as 1.0 . The data are expressed as the mean \pm S.D. $* p<0.05$ when compared with CAI4 cultured in YPD containing FLC

Table 2. MICs of FLC for Different Strains Grown in YPD Containing $20 \mu \mathrm{g} / \mathrm{ml} \mathrm{FLC}$

\begin{tabular}{|c|c|c|c|c|c|c|c|c|}
\hline \multirow{2}{*}{ Strain $^{a}$ ) } & \multicolumn{8}{|c|}{$\operatorname{MIC}_{80}(\mu \mathrm{g} / \mathrm{ml})^{b)}$} \\
\hline & $0 \mathrm{~d}$ & $5 \mathrm{~d}$ & $10 \mathrm{~d}$ & $15 \mathrm{~d}$ & $20 \mathrm{~d}$ & $25 \mathrm{~d}$ & $30 \mathrm{~d}$ & $35 \mathrm{~d}$ \\
\hline CAI4[YPB-ADH] & 0.5 & 0.5 & 1 & 1 & 2 & 8 & 16 & 16 \\
\hline FM7[YPB-ADH] & 1 & 1 & 8 & 32 & $>64$ & $>64$ & $>64$ & $>64$ \\
\hline FM7[YPB-ADH/FCR1] & 0.25 & 0.25 & 0.25 & 0.5 & 1 & 1 & 2 & 4 \\
\hline
\end{tabular}

a) See Table 1 for description of strains. b) Each MIC of FLC was tested in triplicate.

Downregulation of FCR1 Expression in C. albicans Resistant to FLC In this study we used real-time RT-PCR to analyze FCR 1 expression in CAI4 after $25 \mathrm{~d}$ of FLC exposure, and CAI4 cultured for $25 \mathrm{~d}$ without FLC exposure was used as control. The results demonstrated the expression of FCR 1 was decreased by treating the cells with FLC, suggesting it may be involved in the development of FLC resistance in C. albicans (Fig. 2).

FCR1 Inhibited the Development of FLC Resistance in C. albicans The susceptibilities of C. albicans cells to FLC were confirmed by determining the lowest drug concentrations that gave $>80 \%$ inhibition $\left(\mathrm{MIC}_{80}\right)$. To analyze the development of FLC resistance, $C$. albicans were cultured in medium containing FLC at a concentration of $20 \mu \mathrm{g} / \mathrm{ml}$. All strains developed variable degrees of reduced susceptibilities to FLC after $35 \mathrm{~d}$ of drug exposure: the MICs for CAI4[YPB-ADH], FM7[YPB-ADH], and FM7[YPB-ADH/ FCR1] rose from $0.5,1,0.25$ to $16,>64,4$, respectively; an equivalent level of reduced susceptibilities took longer to develop for CAI4[YPB-ADH] than FM7[YPB-ADH], while FM7[YPB-ADH/FCR1] took longer than CAI4[YPB-ADH]; Before the strains exposure to FLC, there were only minor differences in FLC MICs among FM7[YPB-ADH], FM7[YPB-ADH/FCR1] and CAI4[YPB-ADH]; 25 d after FLC exposure FM7[YPB-ADH] was markedly more resistant to FLC than CAI4[YPB-ADH] for which there was a more than 8 fold increase in the MICs, while CAI4[YPB$\mathrm{ADH}$ ] was more resistant to FLC than FM7[YPB-ADH/ FCR1] for which there was an 8 fold increase in the MICs (Table 2).

The agar diffusion test confirmed the above results. From the results of the agar diffusion test to FLC after $25 \mathrm{~d}$ of FLC exposure (Fig. 3), we observed that FM7[YPB-ADH/FCR1]

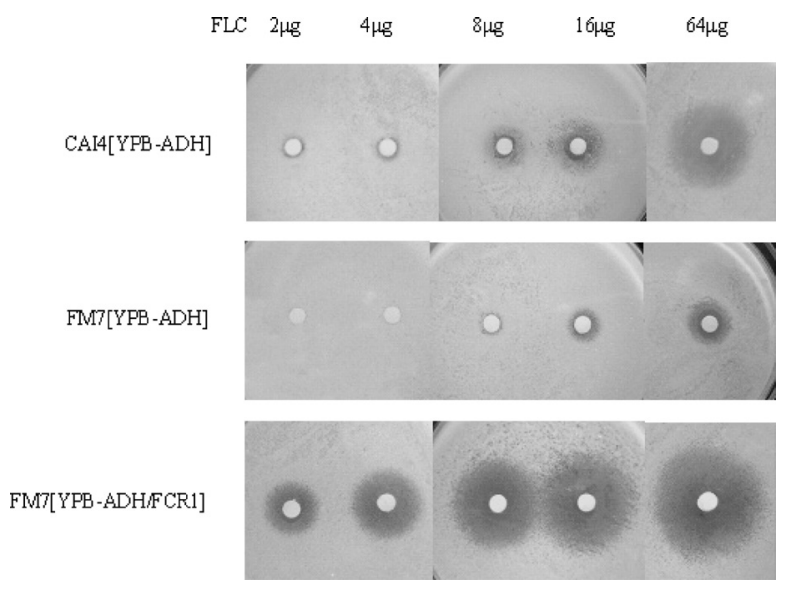

Fig. 3. Agar Disk Diffusion Assay of FLC against CAI4[YPB-ADH], FM7[YPB-ADH] and FM7[YPB-ADH/FCR1] after $25 \mathrm{~d}$ of FLC Exposure

All strains were seeded on YPD agar plates and exposed to FLC $(2 \mu \mathrm{g}, 4 \mu \mathrm{g}, 8 \mu \mathrm{g}$, $16 \mu \mathrm{g}, 64 \mu \mathrm{g}$ ). The plates were incubated at $30^{\circ} \mathrm{C}$ for $48 \mathrm{~h}$

was more sensitive to FLC than CAI4[YPB-ADH] and CAI4[YPB-ADH] was more sensitive than FM7[YPB$\mathrm{ADH}]$, which was evident from the sizes of the zones of inhibition: FM7[YPB-ADH/FCR1] yielded significantly clearer and larger inhibitory zones than CAI4[YPB-ADH] for 2, 4, 8, 16, $64 \mu \mathrm{g} \mathrm{FLC,} \mathrm{and} \mathrm{CAI4[YPB-ADH]} \mathrm{yielded} \mathrm{signifi-}$ cantly clearer and larger inhibitory zones than FM7[YPB$\mathrm{ADH}]$.

The above result was also confirmed by a time growth curve study. After $25 \mathrm{~d}$ of FLC exposure, we observed the influence of $20 \mu \mathrm{g} / \mathrm{ml} \mathrm{FLC} \mathrm{on} \mathrm{the} \mathrm{strains.} \mathrm{The} \mathrm{results} \mathrm{indicated}$ $20 \mu \mathrm{g} / \mathrm{ml}$ FLC had weak activity against FM7[YPB-ADH], but it had powerful activity against FM7[YPB-ADH/FCR1] 


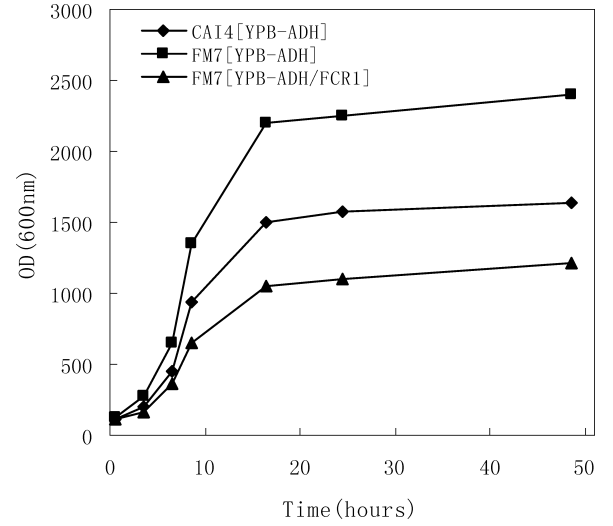

Fig. 4. Effects of FLC $(20 \mu \mathrm{g} / \mathrm{ml})$ on the Growth of FM7[YPB-ADH], FM7[YPB-ADH/FCR1] and CAI4[YPB-ADH] Cultured in YPD Containing $20 \mu \mathrm{g} / \mathrm{ml}$ FLC for $25 \mathrm{~d}$.

Table 3. Fungal Burden in Kidney Tissues of Mice Infected with FM7[YPB-ADH], FM7[YPB-ADH/FCR1] and Treated with FLC

\begin{tabular}{lcc}
\hline \hline \multicolumn{1}{c}{ Strain } & $\begin{array}{c}\text { FLC dosage } \\
(\mathrm{mg} / \mathrm{kg})\end{array}$ & $\begin{array}{c}\text { Median counts } \pm \text { S.D. } \\
\left(\mathrm{CFU} / \mathrm{g}\left[10^{4}\right]\right)\end{array}$ \\
\hline FM7[YPB-ADH/FCR1] & 0 & $121 \pm 35^{*}$ \\
& 5 & $29 \pm 3.2$ \\
FM7[YPB-ADH] & 0 & $198 \pm 51$ \\
& 5 & $176 \pm 49$
\end{tabular}

Data are the mean \pm S.D. of 10 mice. $* p<0.05$ when compared to the group infected with FM7[YPB-ADH/FCR1] by FLC treatment and the group infected with FM7[YPB-ADH]

and showed more marked activity than against CAI4[YPBADH] (Fig. 4).

Antifungal Susceptibility of $F C R 1$ Overexpression and fcrl Mutant Strain after FLC Exposure in Vivo To assess the antifungal susceptibility of FM7[YPB-ADH] and FM7[YPB-ADH/FCR1] after $25 \mathrm{~d}$ of FLC exposure, we performed initial experiments by challenging the mice $(n=10)$ with $1.0 \times 10^{6} \mathrm{CFU}$ per mouse and treated with FLC at a dose of $5 \mathrm{mg} / \mathrm{kg}$ by intravenous injection. Table 3 presents the fungal burdens of FLC treated mice. FLC at the dose of $5 \mathrm{mg} / \mathrm{kg}$ was effective in reducing the number of CFU per gram of kidneys in mice infected with FM7[YPB-ADH/FCR1] $(p<0.05)$, and the same dosing regimen was ineffective in mice infected with the FM7[YPB-ADH].

Overexpression of $F C R 1$ Abolished $C D R 1$ Expression Induced by FLC in the Development of FLC Resistance in C. albicans Overexpression of $C D R 1$, an efflux pump, is one of the major mechanisms contributing to drug resistance in C. albicans. ${ }^{9-11)}$ As a member of a family of zinc cluster proteins, $C$. albicans Fcrlp, homologous to $S$. cerevisiae Pdr1p and Pdr3p, mediated azole resistance by regulating the expression of PDR5 homologous to the C. albicans CDR1, was identified by complementation of the $S$. cerevisiae $p d r l$ $p d r 3$ mutant $^{16)}$ suggesting that Fcrlp might control the expression of $C D R 1$. So we analyzed $C D R 1$ expression in FM7[YPB-ADH], FM7[YPB-ADH/FCR1] and CAI4[YPB$\mathrm{ADH}$ ] after $25 \mathrm{~d}$ of FLC exposure by real-time RT-PCR. As expected in this study, $C D R l$ expression was also induced by FLC exposure in all strains (Fig. 5A). Overexpression of $F C R 1$ abolished the induction of CDR1 expression in the presence of FLC and in contrast fcrl mutant (FM7[YPB-
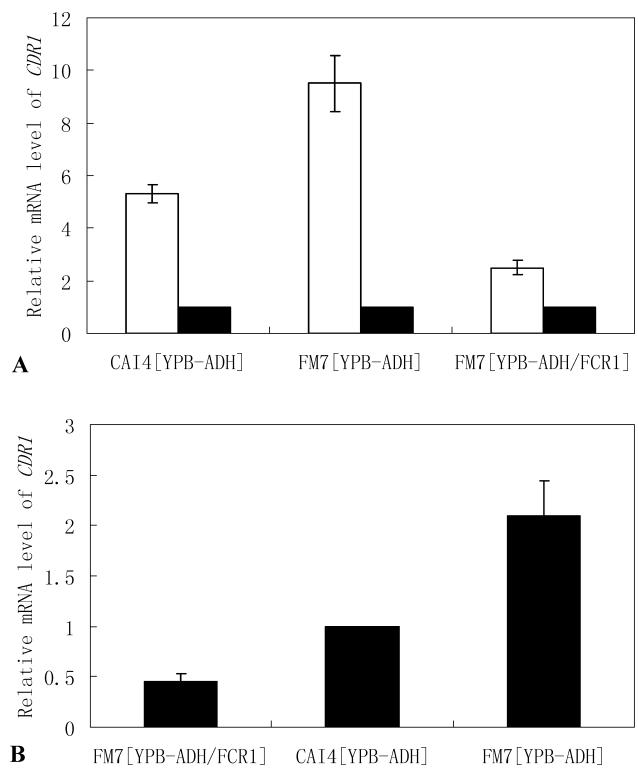

Fig. 5. Overexpression of FCRI in C. albicans Abolished the Induction of $C D R 1$ by FLC

(A) Total RNA was isolated from the strains of CAI4[YPB-ADH], FM7[YPB-ADH], and FM7[YPB-ADH/FCR1] cultured in YPD absent (ם) and present ( $\square$ ) $20 \mu \mathrm{g} / \mathrm{ml}$ FLC for $25 \mathrm{~d}$. The level of mRNA isolated from different strains without FLC exposure was defined as 1.0. The relative level of mRNA isolated from different strains exposure to FLC was normalized to the level of mRNA isolated from the same strain cultured in YPD absent FLC. (B) Relative mRNA level of $C D R 1$ in FM7[YPB-ADH/FCR1], FM7[YPB-ADH] and CAI4[YPB-ADH]. The level of mRNA isolated from wild-type cells (CAI4) was defined as 1.0

$\mathrm{ADH}]$ ) significantly increased the induction of $C D R 1$ expression (Fig. 5A). However, CDR1 expression was not completely abolished by overexpression of $F C R 1$. In the presence of drugs, the level of CDR1 mRNA in the FCR1 overexpression strain was reduced to $45 \%$ of that in the wild-type strain (Fig. 5B).

Overexpression of FCR1 Decreased Efflux of Rhodamine 6G by $C$. albicans in the Development of FLC Resistance To test whether the different susceptibility to FLC among FM7[YPB-ADH], FM7[YPB-ADH/FCR1], CAI4[YPB-ADH] after $25 \mathrm{~d}$ of FLC exposure resulted from the difference in $C D R 1$ expression, we analyzed the efflux of rhodamine $6 \mathrm{G}$ by $C$. albicans. The energy-dependent efflux of rhodamine $6 \mathrm{G}$ was demonstrated: efflux of rhodamine $6 \mathrm{G}$ from the strains required the presence of glucose to provide energy, by $60 \mathrm{~min}$ following glucose addition the extracellular rhodamine $6 \mathrm{G}$ concentration had increased significantly; deletion of FCR1 in C. albicans (FM7[YPB-ADH]) significantly increased the efflux of rhodamine $6 \mathrm{G}$ compared to its parent strain (CAI4[YPB-ADH]) in the presence of FLC, while overexpression of FCR 1 significantly decreased the efflux of rhodamine $6 \mathrm{G}$ compared to its parent strain (CAI4[YPB-ADH]) (Fig. 6).

\section{DISCUSSION}

Widespread and long-term use of azole derivatives to treat C. albicans infection has promoted the development of multidrug resistance. Two major mechanisms of azole resistance have been identified: One common resistance mechanism is the reduced intracellular accumulation of drugs, which is correlated with the increased expression of the $C D R$ genes, members of the $\mathrm{ABC}$ efflux pump family, and/or of the 


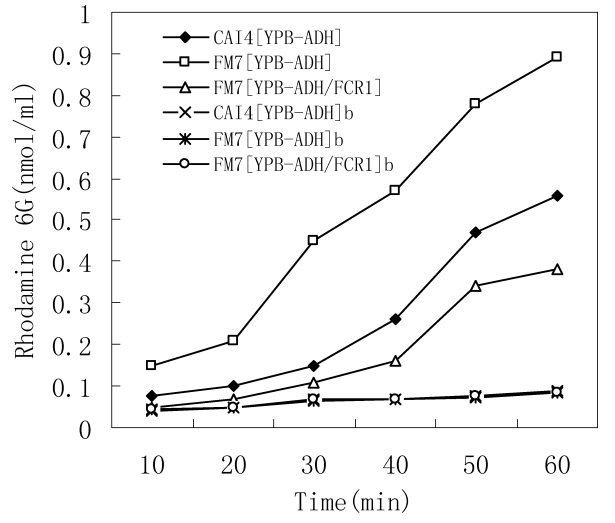

Fig. 6. Energy-Dependent Rhodamine $6 \mathrm{G}$ Efflux from CAI4[YPB-ADH], FM7[YPB-ADH] and FM7[YPB-ADH/FCR1] after $25 \mathrm{~d}$ of FLC Exposure

The florescence in the supernatants of different strains incubated in the presence (CAI4[YPB-ADH], FM7[YPB-ADH], FM7[YPB-ADH/FCR1]) and absence (CAI4[YPB-ADH]b, FM7[YPB-ADH]b, FM7[YPB-ADH/FCR1]b) of glucose (2 mM) was measured. Data are the mean \pm S.D. of triplicate determinations from one experiment for three independent experiments.

MDR1 gene, a member of the MFS efflux pump family. ${ }^{13,31,32)}$ Other common mechanisms are increased expression of the ERG11 gene that encodes the target enzyme of azole drugs, sterol $14 \alpha$-demethylase, and alteration of the enzyme due to point mutations in the gene. ${ }^{32-38)}$

C. albicans FCRl gene has been reported characterization by encoding a putative 517 -amino-acid protein with an N-terminal $\mathrm{Zn}_{2} \mathrm{C}_{6}$-type zinc finger motif homologous to that found in fungal zinc cluster regulatory factors including $S$. cerevisiae Pdr1p and Pdr3p. A previous study found that deletion of FCR 1 gene results in hyperresistance of $C$. albicans to FLC and other antifungal drugs and introduction of a plasmid borne copy of the FCR 1 gene in the $f c r l \Delta / f_{c r} 1 \Delta$ mutant was able to revert the hyperresistance of the cells to a level of susceptibility similar to that of the CAI4 parental strain, indicating that Fcrlp maybe involved in drug resistance of $C$. albicans. ${ }^{16)}$ In this study we observed FCR 1 expression downregulated in the development of FLC resistance in $C$. albicans (Fig. 2), so we further investigated the role of FCR1 in the development of azole resistance in C. albicans.

The results of our study indicated Fcrlp expression inhibited the development of FLC resistance in C. albicans and it was accelerated as a result of deletion of FCR1: after $25 \mathrm{~d}$ FLC exposure to development drug resistance, $\mathrm{MIC}_{80}$ analysis indicated that $f c r l$ mutant strain with no $F C R 1$ expression was markedly more resistant to FLC than the parent strain, while the FCR 1 overexpression strain was more sensitive to FLC than the parent strain (Fig. 1, Table 2); the agar diffusion test and time growth curve study confirmed this vitro result (Figs. 3, 4).

In vivo a mouse model of systemic candidiasis also indicated that the FCR1 overexpression strain was more susceptible to FLC than the $f c r l$ mutant strain after $25 \mathrm{~d}$ of FLC exposure which was consistent with the in vitro results (Table 3 ). Additionally, in this model the $f c r l$ mutant strain was significantly more virulent than the FCR 1 overexpression strain due to the greater number of CFU/g of infected kidney tissues. This suggests that FCRI may also be related to virulence, although further study is needed.

$S$. cerevisiae Pdr1p and Pdr3p, two homologous transcrip- tion factors belonging to the $\mathrm{Zn}_{2} \mathrm{C}_{6}$ binuclear zinc cluster family, have been shown to be involved in drug resistance by upregulating PDR5 and encoding transporters of the ABC efflux pump family. ${ }^{22,25)}$ Fcrlp shares with Pdrlp two functional modules which could be involved in the transcriptional activation of PDR5 in $S$. cerevisiae: a DNA-binding domain to recognize upstream activating sequences in PDR5 and an activation domain to interact with the basal transcriptional machinery. A previous study has shown Fcrlp could control PDR5 expression in the $p d r 1 p d r 3$ mutant strain. ${ }^{16)}$ Therefore in C. albicans, FCR1 homologous to $S$. cerevisiae Pdr1p and Pdr3p might control the expression of the PDR5 homologues $C D R$, encode transporters of the $\mathrm{ABC}$ family, and cause azole resistance. In this study, we found $C D R 1$ upregulated in $C$. albicans fcrl mutant, $F C R l$ overexpression and their parent strain which have reduction susceptibilities to FLC by FLC exposure, but compared to parent strain there was markedly lower induction of $C D R l$ expression in the FCRI overexpression strain and markedly higher in the $f c r l$ mutant strain (Fig. 5). Our results suggested that Fcrlp could partially abolish CDRI induction by FLC in the development of C. albicans azole resistance.

Cdr1p could mediate azole resistance by causing active energy-dependent extrusion of the drug out of cells. ${ }^{31,39)}$ In the present study, we used a fluorescent dye, rhoamine $6 \mathrm{G}$ (R6G), which is a substrate of $C D R 1$, to identify $C D R$ activity because a previous study showed that the efflux of rhoamine $6 \mathrm{G}$ is positively correlated with the expression of $C D R 1{ }^{40)}$ Our results for rhodamine $6 \mathrm{G}$ active efflux also showed that with the susceptibilities of the strains to FLC decreased, and the extrusion of rhodamine $6 \mathrm{G}$ by $C$. albicans increased in the presence of glucose providing energy for rhodamine 6 efflux (Fig. 6), which suggested CDRl overexpression contributed to the development of the reduction susceptibilities to FLC by FLC exposure in this study. The variance of susceptibilities of $C$. albicans FCR 1 overexpression, fcrl mutant and their parent strain to FLC after FLC exposure resulted, at least partially, from the variant expression of CDR1. Taken together, we conclude that Fcr1p may inhibit the development of FLC resistance in C. albicans via abolishing $C D R 1$ induction.

The development of drug resistance and the limited variety of antifungal drugs available for clinical therapy are issues in the treatment of infectious diseases. The present study showed that Fcr1p is involved in the development of C. albicans azole resistance by regulating a drug resistance pathway, though the molecular mechanisms need further study. Hence, our findings may open a new doorway for the development and design of new effective agents for the treatment of microbial infections.

Acknowledgments This work was supported by the National Natural Science Foundation of China (No 303004422).

We thank William A. Fonzi for kindly providing the C. albicans strain CAI4 and Martine Raymond for kindly providing the C. albicans strain FM7 and plasmid YPB-ADHpt.

\section{REFERENCES}

1) Ellis M., Richardson M., De Pauw B., Hosp. Med., 61, 605-609 (2000). 
2) Garber G., Drugs, 61 (Suppl. 1), 1-12 (2001).

3) Maertens J., Vrebos M., Boogaerts M., Eur. J. Cancer Care (Engl.), 10, 56-62 (2001).

4) Pfaller M. A., Jones R. N., Doern G. V., Sader H. S., Messer S. A., Houston A., Coffman S., Hollis R. J., Antimicrob. Agents Chemother, 44, 747-751 (2000).

5) Vanden Bossche H., Warnock D. W., Dupont B., Kerridge D., Sen G. S., Improvisi L., Marichal P., Odds F. C., Provost F., Ronin O., J. Med. Vet. Mycol., 32 (Suppl. 1), 189-202 (1994).

6) Yang Y. L., Lo H. J., J. Microbiol. Immunol. Infect., 34, 79-86 (2001).

7) Boken D. J., Swindells S., Rinaldi M. G., Clin. Infect. Dis., 17, 1018 1021 (1993).

8) White T. C., Marr K. A., Bowden R. A., Clin. Microbiol. Rev., 11 382-402 (1998)

9) Karababa M., Coste A. T., Rognon B., Bille J., Sanglard D., Antimicrob. Agents Chemother, 48, 3064-3079 (2004).

10) Marger M. D., Saier M. H., Jr., Trends Biochem. Sci., 18, 13-20 (1993).

11) Michaelis S., Berkower C., Cold Spring Harbor Symp. Quant. Biol., 60, 291-307 (1995)

12) Prasad R., De Wergifosse P., Goffeau A., Balzi E., Curr. Genet., 27, 320-329 (1995).

13) Sanglard D., Ischer F., Monod M., Bille J., Antimicrob. Agents Chemother, 40, 2300-2305 (1996).

14) Lopez-Ribot J. L., McAtee R. K., Perea S., Kirkpatrick W. R., Rinaldi M. G., Patterson T. F., Antimicrob. Agents Chemother, 43, 16211630 (1999).

15) Puri N., Krishnamurthy S., Habib S., Hasnain S. E., Goswami S. K., Prasad R., FEMS Microbiol. Lett., 180, 213-219 (1999).

16) Talibi D., Raymond M., J. Bacteriol., 181, 231-240 (1999).

17) Balzi E., Chen W., Ulaszewski S., Capieaux E., Goffeau A., J. Biol. Chem., 262, 16871-16879 (1987).

18) Balzi E., Wang M., Leterme S., Van Dyck L., Goffeau A., J. Biol. Chem., 269, 2206-2214 (1994).

19) Decottignies A., Lambert L., Catty P., Degand H., Epping E. A., Moye-Rowley W. S., Balzi E., Goffeau A., J. Biol. Chem., 270, 18150 - 18157 (1995).

20) Delahodde A., Delaveau T., Jacq C., Mol. Cell. Biol., 15, 4043-4051 (1995).

21) Delaveau T., Delahodde A., Carvajal E., Subik J., Jacq C., Mol. Gen.
Genet., 244, 501-511 (1994).

22) Dexter D., Moye-Rowley W. S., Wu A. L., Golin J., Genetics, 136 505-515 (1994).

23) Hallstrom T. C., Moye-Rowley W. S., J. Biol. Chem., 273, 2098-2104 (1998).

24) Katzmann D. J., Burnett P. E., Golin J., Mahe Y., Moye-Rowley W. S., Mol. Cell. Biol., 14, 4653-4661 (1994).

25) Katzmann D. J., Hallstrom T. C., Mahe Y., Moye-Rowley W. S., J. Biol. Chem., 271, 23049-23054 (1996).

26) Katzmann D. J., Hallstrom T. C., Voet M., Wysock W., Golin J., Volckaert G., Moye-Rowley W. S., Mol. Cell. Biol., 15, 6875-6883 (1995).

27) Mahé Y., Parle-McDermott A., Nourani A., Delahodde A., Lamprecht A., Kuchler K., Mol. Microbiol., 20, 109-117 (1996).

28) Meyers S., Schauer W., Balzi E., Wagner M., Goffeau A., Golin J., Curr. Genet., 21, 431-436 (1992).

29) National Committee for Clinical Laboratory Standards, Reference method for broth dilution antifungal susceptibility testing of yeasts Approved standard. Document M27-A2. National Committee for Clinical Laboratory Standards, Wayne, Pa., 2002.

30) Mukhopadhyay K., Kohli A., Prasad R., Antimicrob. Agents Chemother., 46, 3695-3705 (2002).

31) Sanglard D., Kuchler K., Ischer F., Pagani J. L., Monod M., Bille J., Antimicrob. Agents Chemother, 39, 2378-2386 (1995).

32) White T. C., Antimicrob. Agents Chemother, 41, 1482-1487 (1997).

33) Franz R., Kelly S. L., Lamb D. C., Kelly D. E., Ruhnke M., Morshhauser J., Antimicrob. Agents Chemother., 42, 3065-3072 (1998).

34) Loffler J., Kelly S. L., Hebart H., Schumacher U., Lass-Florl C., Einsele H., FEMS Microbiol. Lett., 151, 263-268 (1997).

35) Perea S., Lopez-Ribot J. L., Kirkpatrick W. R., McAtee R. K., Santillan R. A., Martinez M., Calabrese D., Sanglard D., Patterson T. F., Antimicrob. Agents Chemother, 45, 2676-2684 (2001)

36) Sanglard D., Ischer F., Koymans L., Bille J., Antimicrob. Agents Chemother., 42, 241-253 (1998).

37) Vanden Bossche H., Marichal P., Gorrens J., Bellens D., Moereels H., Janssen P. A., Biochem. Soc. Trans., 18, 56-59 (1990).

38) White T. C., Antimicrob. Agents Chemother, 41, 1488-1494 (1997).

39) Sanglard D., Ischer F., Monod M., Bille J., Microbiology, 143, 405416 (1997).

40) Maesaki S., Marichal P., Vanden Bossche H., Sanglard D., Kohno S., J. Antimicrob. Chemother, 44, 27-31 (1999). 